\title{
Knowledge on breast cancer and its prevention among women household heads in Northern Ethiopia
}

\author{
Befikadu Legesse ${ }^{1}$, Teferi Gedif ${ }^{2 *}$ \\ ${ }^{1}$ Department of Pharmacy, Mekelle University, Mekelle, Ethiopia; befikadul@gmail.com \\ ${ }^{2}$ School of Pharmacy, Addis Ababa University, Addis Ababa, Ethiopia; ${ }^{*}$ Corresponding Author: tgedif@gmail.com
}

Received 1 October 2013; revised 9 December 2013; accepted 2 January 2014

Copyright (C) 2014 Befikadu Legesse, Teferi Gedif. This is an open access article distributed under the Creative Commons Attribution License, which permits unrestricted use, distribution, and reproduction in any medium, provided the original work is properly cited. In accordance of the Creative Commons Attribution License all Copyrights (C) 2014 are reserved for SCIRP and the owner of the intellectual property Befikadu Legesse, Teferi Gedif. All Copyright (C) 2014 are guarded by law and by SCIRP as a guardian.

\section{ABSTRACT}

Background: Breast cancer $(\mathrm{BC})$ is one of the malignant diseases taking the lion's share role in the devastating effects caused by cancer. BC related awareness and practice of females are known to have crucial contribution in the prevention and control efforts. The worst aspects of the disease in Ethiopia include absence of research and thus very limited information on any aspect. The study assessed knowledge and practice on $B C$ among women household heads. Methods: A cross-sectional study was conducted on a sample of $\mathbf{8 4 5}$ women. The sample size was divided among five randomly selected kebeles (smallest government administrative units) proportional to the number of households. Samples were selected by systematic sampling technique. Data were collected by trained data collectors through a face-to-face interview using pre-tested, semi-structured questionnaire from female household heads. Pearson chi-square and logistic regression tests were used to assess the determinants of BC knowledge and breast cancer self examination (BSE) practice. Results: The respondents' age ranged from 20 to 75 years with a mean age of $33.66 \pm 10.8$. Onefifth $(19.8 \%)$ of the respondents were illiterate, while $257(31.8 \%)$ had primary education. Majority of them were married $548(67.7 \%)$, Orthodox Christians 649 (80.4\%), and housewives 365 (45.1\%). Only $675(83.4 \%)$ of the respondents have ever heard/read about BC. Media 399 (59.1\%) and colleagues/friends/neighbors 200 (29.6\%) were the major information sources. Only $86(12.7 \%)$ of the respondents had a high BC knowledge. Even though 304 (45\%) of the BC informed participants had information on BSE, only $163(53.6 \%)$ of them have ever done it. Both $B C$ knowledge and BSE practice were significantly affected by educational level. Conclusion: Majority of women household heads in Mekelle town had low knowledge and insufficient BC related practices. The region's health bureau and local mass-media need to work on breast cancer awareness and practice of the women in the town.

\section{KEYWORDS}

Mekelle Town; Breast Cancer; Breast Cancer Knowledge and Practice; Breast Self Examination; Women Household Heads

\section{BACKGROUND}

Breast cancer is the most common cancer diagnosed in women, both in developing and developed countries. It is the second leading cause of death in women worldwide [1]. The burden of the disease is increasing and if no action is taken it might go beyond control [2]. Today, there is no population and woman around the world with a truly low risk of developing breast cancer. The great majority of the burden of BC is expected to fall in low and middle-income countries, where the resources to deal with the current situation, never mind future increases, are absent to a great degree [3]. The widespread belief that the disease is rare in low-income regions such as Africa is a myth. Akarolo-Anthony and colleagues noted that the probability that a woman who lives to age 65 in Uganda would develop cancer is only $20 \%$ lower than that of her European contemporary [4].

Prevention is the best option to tackle the rising epidemic of breast cancer. In this regard, screening, early 
detection and health awareness programs are cornerstones [5]. Public awareness can play a vital role in its prevention, early diagnosis and treatment [6]. BSE is a cost-effective method of early detection of cancer of the breast especially in resource poor countries [7]. Early detection and diagnosis can greatly increase chances for successful treatment and thus increasing awareness of the possible warning signs of the disease among the general public is a necessity [8]. More than $90 \%$ of cases of breast cancer can be detected by women themselves, stressing the importance of breast self-examination (BSE) as the key breast cancer detection mechanism [9]. The problem is that poor awareness of breast cancer symptoms has usually been associated with patient delay in seeking help resulting in reduced survival, more aggressive and fewer treatment options [10].

The worst aspect of the disease in Ethiopia is that there is very little or almost no complete information on any aspect of the problem. In addition, there are no control and prevention programmes against the disease; diagnosis and treatment services are very limited. The findings of a study at Tikur Anbessa Specialized Hospital Radiotherapy Center (the only one in the country) showed that breast cancer is the second most prevalent malignancy accounting for $27.8 \%$ of all cancer cases referred to the hospital [11].

\section{METHODS}

A cross sectional study was conducted in Mekelle town, from September to October, 2011. Mekelle is the capital city of Tigray Regional State, located $783 \mathrm{Km}$ from Addis Ababa to the North of Ethiopia. The town is administratively divided in to 18 kebelles and had a population of 261,177; of whom 134,360 were females [12]. During the survey period, Mekelle town had five hospitals, five health centers as well as twenty private clinics. The majority of the city's population, however, is served by the government owned and operated health facilities [13]. The study population consisted of all women household heads in the town who were 20 years old and above, who resided in the selected kebelles at least for six months and consented to participate in the study.

The sample size was determined using the single population proportion formula [14], assuming the proportion of females with high breast cancer knowledge to be $50 \%$ with a 95\% confidence interval and 5\% sampling error. After considering a design effect of $2 \%$ and $10 \%$ increment for non-response, the sample size was determined to be 845 .

The predetermined sample size was divided among a randomly selected five kebeles proportional to the number of households in each. The required number of samples, from each kebele, was selected by systematic sam- pling technique, employing independent sampling intervals for each. The data collectors made a house-to-house visit in strict adherence to the pre-determined sampling intervals. Only female heads of the sampled households were interviewed. When the woman head in a sampled household was not available in the first visit, data collectors arranged alternative visits. If a woman was not available in all visits or declined to participate in the study, the household was jumped and the immediate next household in the sampling frame was considered. Pretested, semi-structured questionnaire adapted from studies done in Nigeria and Iran [15,16] was used for the data collection. Data were collected by five health professionals specifically trained for this study.

The data were entered to Epi info 3.5.3 and analyzed using SPSS version 16 for windows program. There were twenty-eight questions aimed to assess breast cancer related knowledge. Each right response was given a score of 1 ; while a wrong response was scored 0 . Respondents were categorized based on their overall knowledge scores using the mean \pm standard deviation as cut off points. Therefore the score ranges $[0,6],[7,13]$ and $[14$, 28] were assumed to be low, moderate and high BC knowledge, respectively. Pearson chi-square and logistic regression tests were employed to identify determinants of breast cancer knowldege and BSE practice of the respondents, respectively.

Ethical approval of the study was obtained from School of Pharmacy, Addis Ababa University Ethics Review Committee. The study was conducted after written permeation was obtained from the Regional Health $\mathrm{Bu}-$ reau and the administrators of the kebeles included in the study. Before respondents were requested for consent, they were well informed about the purpose and potential benefits of the study; and participation was on voluntary basis.

\section{RESULTS}

\subsection{Socio-Demographic Characteristics}

Table 1 shows socio-demographic characteristics of the study population. The age of the study participants ranged from 20 to 75 years with a mean age of $33.66 \pm$ 10.8 years. The study had a response rate of $95.7 \%$. Onefifth 160 (19.8\%) of the study participants were illiterate; while 257 (31.8\%) and 105 (13\%) had primary and college/university education, respectively. Majority 548 $(67.7 \%)$ of the study participants were married. About four-fifth 649 (80.4\%) of the women included in the study were Orthodox Christians, while 122 (15.1\%) were Muslims. Three hundred sixty five (45.1\%) of the women were housewives; followed by merchants 147 (18.2\%). 
Table 1. Socio-demographic characteristics of the study population, Mekele, Northern Ethiopia.

\begin{tabular}{|c|c|c|c|}
\hline Characteristic & & Number & Percentage \\
\hline \multirow[t]{5}{*}{$\begin{array}{l}\text { Age distribution } \\
(\mathrm{n}=809)\end{array}$} & $20-29$ & 327 & 40.4 \\
\hline & $30-39$ & 282 & 34.9 \\
\hline & $40-49$ & 118 & 14.6 \\
\hline & $\geq 50$ & 82 & 10.1 \\
\hline & Mean (SD) & $\begin{array}{l}33.66 \\
(10.8)\end{array}$ & \\
\hline \multirow[t]{6}{*}{$\begin{array}{l}\text { Educational status } \\
\qquad(\mathrm{n}=809)\end{array}$} & Illiterate & 160 & 19.8 \\
\hline & Non-formal education & 50 & 6.2 \\
\hline & Primary & 257 & 31.8 \\
\hline & Secondary & 152 & 18.8 \\
\hline & TVET & 85 & 10.5 \\
\hline & College/University & 105 & 13.0 \\
\hline \multirow[t]{4}{*}{$\begin{array}{l}\text { Marital Status } \\
\quad(\mathrm{n}=809)\end{array}$} & Married & 548 & 67.7 \\
\hline & Divorced & 78 & 9.6 \\
\hline & Widowed & 118 & 14.6 \\
\hline & Single & 65 & 8.1 \\
\hline \multirow[t]{4}{*}{ Religion $(\mathrm{n}=806$ ) } & Orthodox & 649 & 80.4 \\
\hline & Islam & 122 & 15.1 \\
\hline & Protestant & 22 & 2.7 \\
\hline & Catholic & 13 & 1.6 \\
\hline \multirow[t]{6}{*}{$\begin{array}{l}\text { Occupation } \\
(\mathrm{n}=808)\end{array}$} & Housewife & 365 & 45.1 \\
\hline & Government employee & 104 & 12.9 \\
\hline & Merchant & 147 & 18.2 \\
\hline & Daily laborer & 40 & 4.9 \\
\hline & Student & 79 & 9.8 \\
\hline & Others ${ }^{*}$ & 73 & 9.0 \\
\hline
\end{tabular}

*jobless, farmer, handicrafts, carpenter, retired. TVET $=$ Technical and Vocational Education and Training

\subsection{Breast Cancer Information Sources and Knowledge}

Six hundred seventy five (83.4\%) of the study participants reported that they have ever heard or read about breast cancer and further interviews were continued only with these study participants. As shown in Figure 1, media (television, radio and newspaper) was reported as a major source of information for nearly three-fifth of the study participants. Two hundred (29.6\%) of the respon-

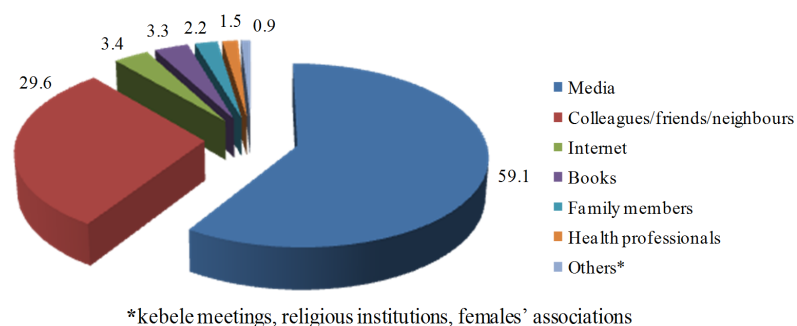

Figure 1. Major breast cancer information sources.

dents who reported to have had information on breast cancer mentioned colleagues/friends/neighbors as their major information source. The contribution of health professionals as a source of breast cancer related information was found to be very minimal $10(1.5 \%)$.

The overall knowledge score of the respondents ranged from 6 to 24, with a mean of 9.29 (SD = 3.501); out of the 28 questions designed to assess BC knowledge of the respondents. Two hundred thirty four (34.7\%) of the respondents had a knowledge score of greater than or equal to the mean knowledge score. Three hundred ten (45.9\%) and 279 (41.3\%) of the respondents had a low and moderate knowledge level, respectively; while 86 (12.7\%) had a high knowledge level. The proportion of respondents who identified cigarette smoking, alcohol consumption and radiation exposure as risk factors for breast cancer was 236 (35\%), 160(23.7\%) and 119 (17.6\%), respectively. With regard to symptoms of BC, breast lump 455 (67.4\%), breast pain 275 (40.7\%) and nipple rash 96 (14.2\%) were commonly mentioned.

As presented in Table 2, majority 609 (90.2\%) of breast cancer informed women knew that early diagnosis of breast cancer improves chances of survival; and 439 (65\%) of them indicated clinical breast examination (CBE) as a method of breast cancer detection. Only about one-fifth 140 (20.7\%) of the respondents who had information on breast cancer mentioned BSE as a method of breast cancer detection. Mammography was known by very few 31 (4.6\%) of the respondents. Three hundred eighty three $(56.7 \%)$ of the breast cancer informed women said that breast cancer is a curable disease; of whom 244 (63.7\%) indicated that biomedical treatment is preferred method to cure the disease.

Three hundred four (45\%) of the women who reported to have had breast cancer information have ever heard/ read about BSE. The major source of information on BSE for nearly three-fifth 178 (58.5\%) of the respondents who had information was media followed by colleagues/friends/neighbors 74 (24.3\%). Forty-one (13.5\%) of the study participants know that BSE should be started at the age of 20 or less, while $204(67.1 \%)$ believed it should be started after the age of 20 years. Fifty-nine (19.4\%) respondents don't know at what age BSE should be commenced. 
Table 2. Knowledge on breast cancer diagnosis and treatment.

\begin{tabular}{|c|c|c|}
\hline Questions & Responses & $\mathrm{N}(\%)$ \\
\hline Does early detection of breast cancer improve chances of survival? & $\begin{array}{c}\text { Yes } \\
\text { No } \\
\text { Don't know }\end{array}$ & $\begin{array}{c}609(90.2) \\
16(2.3) \\
50(7.4)\end{array}$ \\
\hline What methods of breast cancer detection you know?* & $\begin{array}{c}\text { BSE } \\
\text { CBE } \\
\text { Mammography } \\
\text { Don't know }\end{array}$ & $\begin{array}{c}140(20.7) \\
439(65.0) \\
31(4.6) \\
81(12.0)\end{array}$ \\
\hline Is $\mathrm{BC}$ a treatable disease? & $\begin{array}{c}\text { Yes } \\
\text { No } \\
\text { Don’t know }\end{array}$ & $\begin{array}{l}383(56.7) \\
150(22.2) \\
142(21.0)\end{array}$ \\
\hline Which form of treatment is preferable? $(\mathrm{n}=383)$ & $\begin{array}{c}\text { Biomedical } \\
\text { Traditional } \\
\text { Holy water } \\
\text { Others }^{* *}\end{array}$ & $\begin{array}{c}244(63.7) \\
71(18.5) \\
59(15.4) \\
9(2.3)\end{array}$ \\
\hline Which form of Biomedical treatment is the best? $(\mathrm{n}=244)$ & $\begin{array}{c}\text { Chemotherapy } \\
\text { Radiation } \\
\text { Surgery } \\
\text { Don't know }\end{array}$ & $\begin{array}{l}62(25.4) \\
33(13.5) \\
79(32.4) \\
70(28.7)\end{array}$ \\
\hline Reason for not preferring BT $(\mathrm{n}=139)$ & $\begin{array}{l}\text { Less efficacious } \\
\text { Unavailable } \\
\text { Unaffordable } \\
\text { No reason }\end{array}$ & $\begin{array}{c}62(44.6) \\
35(25.2) \\
8(5.7) \\
34(24.5)\end{array}$ \\
\hline
\end{tabular}

"percentages don’t add up to hundred as a respondent may give more than one response; ${ }^{* *}$ witchcraft, physical therapy/massage.

\subsection{Breast Cancer Related Practices}

Among the 304 study participants who had information on BSE, only 163 (53.6\%) have ever done BSE and only $46(29.5 \%)$ of them reported to practice it on a regular monthly basis. The age at which the study participants started BSE ranged from 13 to 56 year with a mean age of $24.92 \pm 7.2$. Among 152 women who practiced BSE and could report the age at which they started the practice, only 61 (40.1\%) commenced it at the age of 20 years or less. The main reasons given for performing BSE were fear of breast cancer \& other diseases 105 (64.4\%) and unusual appearances of their breasts 38 (23.3\%). Eighty nine (54.6\%) of the BSE performers claimed to have a regular BSE performance of varying frequencies. Greater than half (55.5\%) of the BSE non-performing study participants believed that they have some kind of barrier to practice BSE. Absence of symptoms or disease, doubt about its effectiveness and forgetfulness were mentioned as main barriers to perform BSE by 149 (52.3\%), 78 (27.5\%) and 38 (13.4\%) of the respondents, respectively (Table 3 ).

Only $81(12.2 \%)$ of the respondents have ever had CBE, of whom 34 (42\%) had it only once before the study. Absence of symptoms or disease and not knowing the need were the main reasons mentioned by 220 (38.7\%) and 214 (37.6\%), respectively, of the respondents who never had CBE. Concerning mammography, only $18(2.7 \%)$ have ever had it. The main reasons given by the women for their failure to have had mammogra- phy were doubt about its importance 215 (33.8\%), not knowing as they should had it 203 (31.9\%) and unavailability of the service 89 (14.0\%).

\subsection{Determinants of Breast Cancer Knowledge and Breast Self-Examination Practice}

The present study indicated that educational level $\left(\mathrm{X}^{2}\right.$ $=29.427, \mathrm{p}=0.000)$ and occupation $\left(\mathrm{X}^{2}=38.364, \mathrm{p}=\right.$ 0.000 ) of the respondents were found to have significant influence on their overall breast cancer knowledge. Among 639 participants with complete information on education and knowledge score, we found that relatively higher percentage (29\%) of the women with tertiary education had high knowledge as compared to illeterates and non-formally educated (13.3\%) and women with primary, secondary and TVET educational status. Much less percentage of merchants 6 (5.3\%) and housewives 31 (10\%) had a high knowledge score relative to government employees 20 (20\%), students 14 (19.2\%), daily laborer, jobless and others 15 (19\%). Other socio-demographic variables were not found to have significant influence on breast cancer knowledge score (Table 4).

Our results indicated that as age increases, the proportion of women performing BSE decreases i.e. 28.2\% for the age group 20 - 29 years to $15.8 \%$ among those of 50 years and older; but the logistic regression result showed that age was not significantly associated with BSE practice of the women. The proportion of women having col- 
Table 3. Practice of breast self-examination.

\begin{tabular}{|c|c|c|c|}
\hline Question & Responses & Number & Percentage \\
\hline \multirow[t]{4}{*}{ Reason to perform BSE ( $n=163$ ) } & Fear of BC \& other diseases & 105 & 64.4 \\
\hline & Family history of BC & 4 & 2.4 \\
\hline & Unusual appearance of breast & 38 & 23.3 \\
\hline & Others $^{*}$ & 16 & 9.8 \\
\hline \multirow[t]{5}{*}{ Frequency of BSE performance $(n=156)$} & & & \\
\hline & Dany to weekily & 56 & 35.9 \\
\hline & Monthly & 46 & 29.5 \\
\hline & Yearly & 10 & 6.4 \\
\hline & Occasionally & 44 & 28.2 \\
\hline \multirow[t]{6}{*}{ Reasons for not performing BSE $(n=675)$} & & & \\
\hline & I don't think it is important & 80 & 15.9 \\
\hline & I don't know how to do it & 138 & 27.5 \\
\hline & I don't have any symptom & 32 & 6.4 \\
\hline & I know I can never have BC & 198 & 39.4 \\
\hline & Others $^{* *}$ & 54 & 10.7 \\
\hline \multirow[t]{5}{*}{ Barriers to perform BSE $(n=284)$} & Lack of privacy & 3 & 1.0 \\
\hline & Pressure of work & 16 & 5.6 \\
\hline & Doubt about its effectiveness & 78 & 27.5 \\
\hline & Absence of symptom/disease & 149 & 52.3 \\
\hline & Forgetfulness & 38 & 13.4 \\
\hline
\end{tabular}

"promotional information, just a habit, looking others doing it; ${ }^{* *}$ fear of being diagnosed with breast cancer, “I shouldn’t touch my body like that” thought.

Table 4. Determinants of breast cancer related knowledge.

\begin{tabular}{|c|c|c|c|c|c|}
\hline \multirow{2}{*}{$\begin{array}{l}\text { Background } \\
\text { Characteristics }\end{array}$} & & \multicolumn{2}{|c|}{ Knowlege level [count(percentage)] } & \multirow[t]{2}{*}{ Pearson $X^{2}$} & \multirow[t]{2}{*}{ p-value } \\
\hline & & Low \& moderate & High & & \\
\hline \multirow[t]{4}{*}{ Age (years) } & $20-29$ & $258(87.7)$ & $36(12.2)$ & 0.448 & 0.930 \\
\hline & $30-39$ & $203(86.4)$ & $32(13.6)$ & & \\
\hline & $40-49$ & $71(86.6)$ & $11(13.4)$ & & \\
\hline & $>50$ & 57 (89.1) & 7 (10.9) & & \\
\hline \multirow[t]{3}{*}{ Educational level } & "Illiterate”,** & $113(86.9)$ & $17(13.1)$ & 29.427 & $0.000^{*}$ \\
\hline & $1^{0}, 2^{0} \&$ TVET & $405(91)$ & $40(9)$ & & \\
\hline & Tertiary $^{* * *}$ & $71(71)$ & $29(29)$ & & \\
\hline \multirow[t]{2}{*}{ Religion } & Christian & $502(86.2)$ & $80(13.7)$ & 3.837 & 0.051 \\
\hline & Islam & 87 (93.5) & $6(6.4)$ & & \\
\hline \multirow[t]{2}{*}{ Marital status } & Married & 415 (87) & $62(13)$ & 0.373 & 0.542 \\
\hline & Others & $173(88.7)$ & $22(11.3)$ & & \\
\hline \multirow[t]{5}{*}{ Occupation } & Housewife & $279(90)$ & $31(10)$ & 38.364 & $0.000 *$ \\
\hline & Government employee & $80(80)$ & $20(20)$ & & \\
\hline & Merchant & $106(95.7)$ & $6(5.3)$ & & \\
\hline & Student & $59(80.8)$ & $14(19.2)$ & & \\
\hline & Daily laborer, jobless and others & $64(81)$ & $15(19)$ & & \\
\hline
\end{tabular}

"significant association, ${ }^{* *}$ “Illiterate” includes respondents with no education and non-formal education, ${ }^{* * *}$ Tertiary includes college and university. 
lege/university education who performed BSE was more than the proportion in the illiterate or with non-formal education (48.5\% versus $18.2 \%$ ). This difference was found to be statistically significant $(\mathrm{AOR}=4.65,95 \% \mathrm{CI}$ $=2.19$ - 9.86). Even though higher percentage of the women with personal and family history of breast cancer practiced BSE as compared to those with no personal and family history of the disease, neither were found to have significant association with BSE practice. Similarly, BSE practice of the women was not found to be significantly affected by their religion and marital status. History of breast problems other than breast cancer $(\mathrm{AOR}=2.28$, $95 \% \mathrm{CI}=1.14-4.33$ ) and breast cancer knowledge score $(\mathrm{AOR}=3.02,95 \% \mathrm{CI}=2.20-10.67)$ of the respondents were significantly related to their BSE practice (Table 5).

\section{DISCUSSION}

This study was focused on females aged 20 years and above. This was because females are predominantly af- fected by the disease $[17,18]$ and almost all breast cancer screening techniques are applicable to females older than 20 years [19].

Concur to the findings of the study done among rural Nigerian women, the present study revealed that $83.4 \%$ of the women have ever heard or read about breast cancer [20]. Three-fifth (59.1\%) of those who had breast cancer information indicated that their major source of information was media. Colleagues/friends/neighbors were also mentioned as important sources of information on breast cancer. Surprisingly, the proportion of respondents who mentioned health professionals as major source of breast cancer information was very small. This is consistent to the findings of a similar study conducted among Pakistani females where relatives, friends and neighbors were found to be the main sources of breast cancer information while only $7.2 \%$ of females mentioned health care providers as sources of BC realted information [21].

Table 5. Determinants of breast self-examination practice.

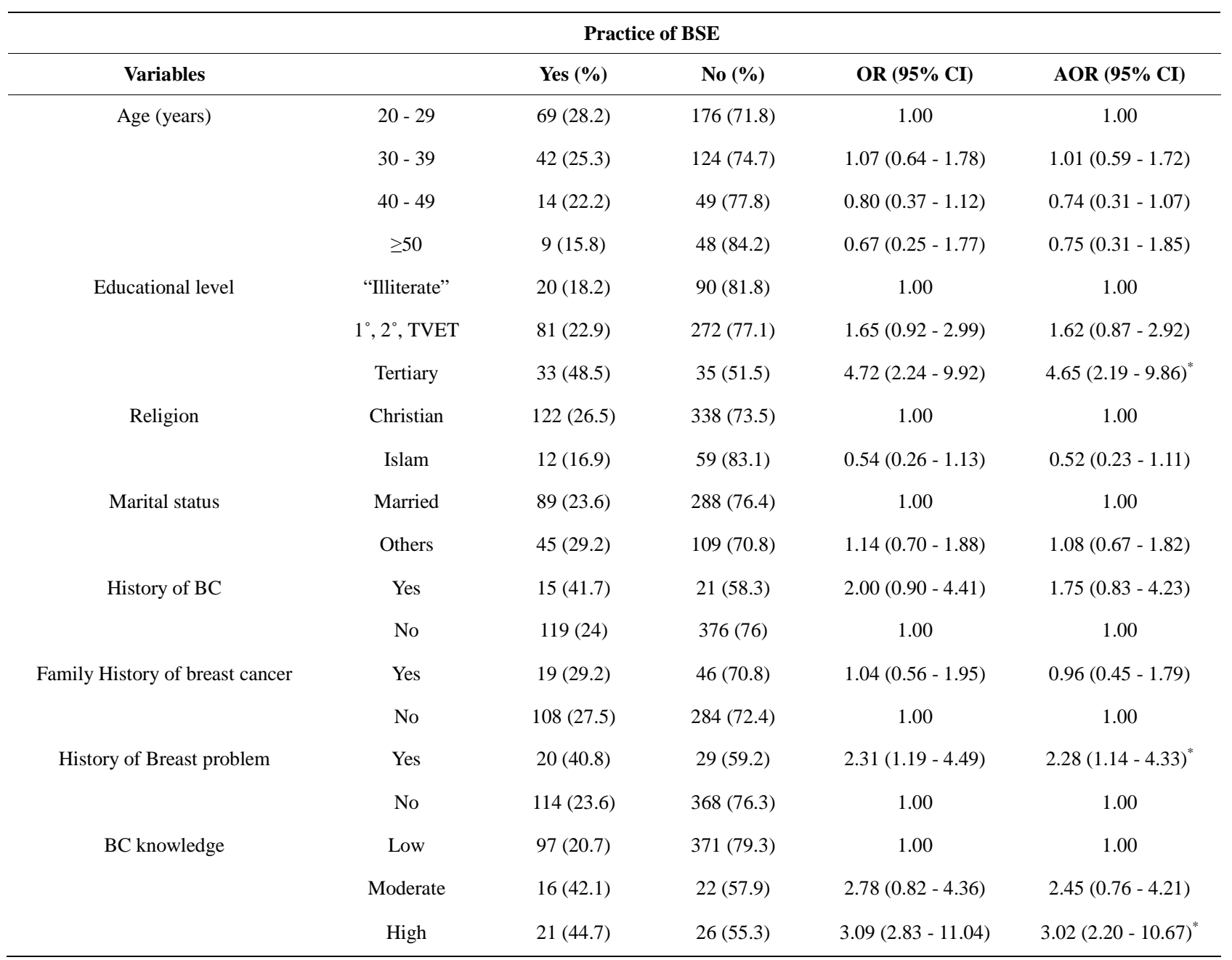

*significant associations. 
The mean breast cancer knowledge score was $9.3 \pm$ 3.5. Only 86 (12.7\%) of the women had high knowledge level. A better breast cancer knowledge level was obtained in a study among Nigerian women [15]. This difference could be due to the fact that larger proportion of the women in that study were singles and younger $(61.9 \%$ were under the age of $30 \%$ and $46.1 \%$ were singles) than the present study, which would make them more cautious about health problems affecting their beauty and physical appearance, might also have contributed for their better knowledge level.

In the present study, large proportion (90.2\%) of breast cancer informed participants knew that early detection of breast cancer improves chances of survival from the disease. A contrasting result to this was reported from a study among Jordanian women where the study participants said that detecting it in an early or late state wouldn't change the course of the disase [22]. There was no single respondent who mentioned adverse effects of the drugs as a barrier to use modern medicine. This is not in line with the fact that adverse drug reactions are one of the challenges in the treatment of breast cancer [3].

Regarding BSE knowledge of the women, $45 \%$ of those who had information on breast cancer have ever heard/read about BSE. A study of BSE behavior among Chinese immigrant women indicated that $80.9 \%$ reported having heard of BSE [23]. Another study on a group of women in a rural area of Western Turkey found that $72.1 \%$ of the respondents had knowledge about BSE [23]. The relatively low knowledge of our respondents about BSE might preclude them from practicing BSE, which might lessen chances of early detection of the disease. Since the proportion of respondents receiving BSE information from colleagues/friends/neighbors is very high as compared to those who depend on books, internet or health professionals, chances of getting biased information might be significant. In addition, the reason why health professionals were not serving as major source of information on BSE related issues needs to be investigated.

The present study showed that among the respondents who reported to have had information on breast cancer, only $20.1 \%$ have ever done BSE, less than a third of them performing it on a regular monthly basis. The study among women in Iran found that $17 \%$ of the respondents were performing regular monthly BSE. The main reason mentioned by non-performers was lack of knowledge on how to do it (64.0\%) [16]. Lowest rate of BSE performance was reported by Jordanian women in which only $7 \%$ of the participants reported practicing BSE on a regular monthly basis [22].

The major barriers for practicing BSE identified in the present study were absence of the symptoms and lack of knowledge about its importance. In a cross-sectional survey among 357 Kuwait women, the main reasons for not performing BSE were fear of cancer discovery
(13.4\%), forgetfulness (14.5\%), failure to realize the importance of BSE (15.3\%) and lack of knowledge about the technique of BSE (28.9\%) [24]. In another study among Iranian women the common reasons given for not doing BSE include lack of knowledge (48\%), forgetfulness (20\%), fear of finding a mass (17\%), no necessary belief (9\%) and lack of time (4\%) [25]. A study among American women reported that $96 \%$ of them had knowledge about BSE, but only $19 \%$ - $40 \%$ performed it on a monthly basis [26]. This practice knowledge gap needs to be adreessed inorder to tackle the disase in these countries.

Having university/college education and engagement in occupations other than housewife and merchant were associated with higher breast cancer knowledge scores. These results are in agreement with findings that were reported by Okobia and colleagues [15] among Nigerian women. Other demographic variables including age, marital status and religion were not significantly related to knowledge score.

Having college/university education, having personal history of breast problems and breast cancer knowledge score of $50 \%$ and above were significant determinants of practicing BSE. In this respect, College/university educated respondents were found to have nearly five times better BSE performance than others. Women with a high breast cancer knowledge score were six times more likely to perform BSE relative to those with a low breast cancer knowledge score. Even though BSE practice was found to have relation with other variables (age, religion, marital status, personal history of breast cancer and family history of breast cancer), statistically significant association was obtained with none of them. Okobia and colleagues [15] reported a more or less similar finding to this study. In their study higher level of education and higher knowledge score were significant determinants of BSE practice.

\section{CONCLUSION}

The study revealed that majority of the women household heads in Mekelle town had low breast cancer knowledge. Small proportion of the women was found to have experiences of breast cancer related beneficial practices: performing BSE, having CBE and having mammography. Educational level and occupation were found to have significant association with breast cancer knowledge score; while BSE practice of the women was found to be significantly affected by educational level, breast cancer knowledge and history of breast problems other than breast cancer.

\section{ACKNOWLEDGEMENTS}

We are much grateful to the participants of the study, the data col- 
lectors and the administrators of the sampled kebelles. The invaluable contribution of the Department of Pharmacy, College of Health Sciences, Mekelle University and colleagues during the data collection is appreciated. We should also thank Tigray Region Health Bureau for the help in providing all the information we were in need. We would like to extend our acknowledgement to the School of Graduate Studies, Addis Ababa University for sponsoring the research.

\section{REFERENCES}

[1] Parkin, D.M., Bray, F., Ferlay, J. and Pisani, P. (2005) Global cancer statistics, 2002. CA: A Cancer Journal for Clinicians, 55, 74-108.

http://dx.doi.org/10.3322/canjclin.55.2.74

[2] Smith, R.A., Caleffi, M., Albert, U., Chen, T.H.H., Duffy, S.W., Franceschi, D. and Nyström, L. (2006) Breast cancer in limited resource countries: Early detection and access to care. Breast Journal, 12, S16-S26. http://dx.doi.org/10.1111/j.1075-122X.2006.00200.x

[3] Boyle, P. and Howell, A. (2010) The globalisation of breast cancer. Breast Cancer Research, 12, S7. http://dx.doi.org/10.1186/bcr2736

[4] Akarolo-Anthony, S.N., Ogundiran, T.O. and Adebamowo, C.A. (2010) Emerging breast cancer epidemic: Evidence from Africa. Breast Cancer Research, 12, S8. http://dx.doi.org/10.1186/bcr2737

[5] Shallwani, K., Ramji, R., Ali, T.S. and Khuwaja, A.K. (2010) Self-examination for breast and testicular cancers: a community-based intervention study. Asian Pacific Journal of Cancer Prevention, 11, 145-148.

[6] Ali, T.S., Baig, S. (2006) Evaluation of a cancer awareness campaign: experience with a selected population in Karachi. Asian Pacific Journal of Cancer Prevention, 7, 391-395.

[7] Gwarzo, U.M.D., Sabitu, K. and Idris, S.H. (2009) Knowledge and practice of BSE among female undergraduate students of Ahmadu Bello University Zaria, Northwestern Nigeria. Annals of African Medicine, 8, 55-58. http://dx.doi.org/10.4103/1596-3519.55766

[8] Mon, M.M., Mon, M. and Than, K.K. (2009) Women's awareness, knowledge and perceived magnitude regarding common female cancers in Yangon, Myanmar. Asian Pacific Journal of Cancer Prevention, 10, 1047-1050.

[9] Meijer-van Gelder, M.E., Look, M.P., Vries, J.B., Peters, H.A., Klijn, J.G. and Foekens, J.A. (2001) Clinical relevance of biologic factors in male breast cancer. Breast Cancer Research and Treatment, 68, 249-260. http://dx.doi.org/10.1023/A:1012221921416

[10] Jones, S.C., Gregory, P., Nehill, C., Barrie, L., Luxford, K., Nelson, A., Zorbas, H. and Iverson, D. (2010) Australian women's awareness of breast cancer symptoms and responses to potential symptoms. Cancer Causes Control, 21, 945-958.

http://dx.doi.org/10.1007/s10552-010-9522-9

[11] Assefa, M. (2011) Assessment of types and treatment pattern of cancer in TASH Radiotherapy Center: Retrospective study. A Thesis Submitted to the School of Grad- uate Studies of AAU in partial fulfillment of the requirements for the Degree of Master of Science in Pharmacoepidemiology and Social Pharmacy, Addis Ababa.

[12] Central Statistical Agency of Ethiopia: Statistical tables for the 2007 Population and Housing Census of Ethiopia. (2008)

http://www.csa.gov.et/index.php?option=com_rubberdoc $\underline{\text { \&view }=\text { category\&id }=72 \text { \&Itemid }=521 \text { \&limitstart }=20}$

[13] TRHB (2010) The Tigrai Health Bureau Profile of 2010. www.trhb.gov.et

[14] WHO (2001) Sampling methods and sample size. In: Omi S. Health research methodology: A guide for training in research methods. 2nd Edition, Manila, 71-84.

[15] Okobia, M.N., Bunker, C.H., Okonofua, F.E., Osime, U. (2006) Knowledge, attitude and practice of Nigerian women towards breast cancer: A cross-sectional study. World Journal of Surgical Oncology, 4, 11. http://dx.doi.org/10.1007/s10552-010-9522-9

[16] Montazeri, A., Vahdaninia, M., Harirchi, I., Harirchi, A.M., Sajadian, A., Khaleghi, F., Ebrahimi, M., Haghighat, S. and Jarvandi, S. (2008) Breast cancer in Iran: Need for greater women awareness of warning signs and effective screening methods. Asia Pacific Family Medicine, 7, 6. http://dx.doi.org/10.1186/1447-056X-7-6

[17] Teresa, D.H., Harry, J.K., Jerzy, E.T. and Hans, J.B. (2005) Comparison of male and female breast cancer incidence trends, tumor characteristics, and survival. Annals of Epidemiology, 15, 773-780.

http://dx.doi.org/10.1016/j.annepidem.2005.01.001

[18] William, F.A., Ismail, J., Julia, T. and Philip, S.R. (2010) Male breast cancer: A population-based comparison with female breast cancer. Journal of Clinical Oncology, 28, 232-239. http://dx.doi.org/10.1200/JCO.2009.23.8162

[19] Baines, C.J. (1992) Breast Self Examination. Cancer, 69, 1942-1946.

http://dx.doi.org/10.1002/1097-0142(19920401)69:7+<19 42::AID-CNCR2820691712>3.0.CO;2-K

[20] Oluwatosin, O.A. and Oladepo, O. (2006) Knowledge of breast cancer and its early detection measures among rural women in Akinyele Local Government Area, Ibadan Nigeria. BMC Cancer, 6, 271. http://dx.doi.org/10.1186/1471-2407-6-271

[21] Gilani, S.I., Khurram, M., Mazhar, T., Mir, S.T., Ali, S., Tariq, S. and Malik, A.Z. (2010) Knowledge, attitude and practice of a Pakistani female cohort towards breast cancer. Journal Pakistan Medical Association, 62, 205-208.

[22] Petro-Nustus, W. and Mikhail, B.I. (2002) Factors associated with BSE among Jordanian women. Public Health Nursing, 19, 263-271. http://dx.doi.org/10.1046/j.1525-1446.2002.19406.x

[23] Dündar, P.E., Özmen, D., Öztürk, B., Haspolat, G., Akyıldız, F., Çoban, S. and Çakıroğlu, G. (2006) The knowledge and attitude of BSE and mammography in a group of women in a rural area in western Turkey. BMC Cancer, 6, 43-52. http://dx.doi.org/10.1186/1471-2407-6-43

[24] Al-Qattan, M.M., Al Saleh, K.A., Al-Musallam, S.S. and Masoud, G.M. (2008) Knowledge and factors affecting 
breast self-examination among Kuwaiti women. Kuwait Medical Journal, 40, 103-110.

[25] Parisa, P. and Kandiah, M. (2005) Breast cancer knowledge, perception and BSE practices among Iranian women. The International Medical Journal, 4, 17-24.
[26] Coleman, E.A. (1991) Practice and effectiveness of BSE: A selective review of the literature (1977-1989). Journal of Cancer Education, 6, 83-92.

http://dx.doi.org/10.1080/08858199109528096 